\title{
The Derivation of Wh-Questions in Najrani Arabic
}

\author{
Saud A. Mushait \\ Department of English, Faculty of Languages \\ Najran University, Saudi Arabia \\ E-mail: smushait@gmail.com
}

Received: August 8, 2019 Accepted: August 23, 2019 Published: October 16, 2019

doi:10.5296/ijl.v11i5.15238

URL: https://doi.org/10.5296/ij1.v11i5.15238

\begin{abstract}
The study explores the derivation of wh-questions in Najrani Arabic and attempts to answer the following questions: (i) Can wh-questions in Najrani Arabic be derived in VSO or SVO or both?, and (ii) How can Najrani Arabic wh-questions be accounted for within Chomsky's (2001,2005, 2013,2015 ) Phase approach? The objective of the study is to present a unified analysis of the derivation of wh-questions in Najrani Arabic and show the interaction between Najrani Arabic data and Chomsky's Phase framework. It has been shown that Najrani Arabic allows the derivation of wh-questions from the argument and non-argument positions in VSO word order. Given this, we assume that VSO is the unmarked order for the derivation of wh-questions in Najrani Arabic. In VSO, the subject DP does not raise to Spec-TP because the head T does not have the EPP feature: the latter attracts movement of the former. The verb raises to the head $\mathrm{T}$ of TP, while the subject DP remains in-situ in Spec-vP. Moreover, in Najrani Arabic intransitive structures, the phase vP does not have a specifier because it does not have an external thematic argument whereas in transitive constructions the $\mathrm{vP}$ has. Concerning case assignment, the phase $\mathrm{vP}$ merges with an abstract tense af (fix) on the head $\mathrm{T}$, which agrees with and assigns invisible nominative case to the subject wh-word man 'who'. We assume that the phase head $\mathrm{C}$ is the probe and has the Edge feature which attracts the raising of the subject wh-phrase to Spec-CP. Besides, we argue that the light transitive head $\mathrm{v}$ has an Edged feature which attracts the raising of the object wh-phrase aish 'what' to be the second (outer) specifier of vP. Being the phase head, the v probes for a local goal and finds the object wh-phrase aish; the v agrees with and assigns accusative case to the object wh-phrase aish. As the TP merges with a null interrogative head $\mathrm{C}$, the phase head $\mathrm{C}$ has an Edge feature that attracts the raising of the object wh-word aish to Spec-CP for feature valuation. Following this, the null copies of the moved entities left after movement receive a null spellout in the phonological level and, hence, cannot be accessed for any further operation.
\end{abstract}

Keywords: vP phase, CP, Wh-questions, Edge feature, Phase head, Merge, Najrani Arabic 


\section{Introduction}

The syntactic analysis of wh-questions in natural language grammar has received considerable attention in the last thirty years of generative syntax, in general, and in Standard Arabic and Arabic dialects, in particular. Wh-question movement has been the focus of extensive syntactic analysis in Chomsky's (1981-1991) Government and Binding theory and the Minimalist Program (1995-2015) and other analyses of many syntacticians. Furthermore, various accounts have been made to explore and analyze wh-questions in Standard Arabic and Arabic dialects with the aim of presenting a unified treatment of the subject under investigation. This can be observed in works on Standard Arabic by Alotaibi (2013); Al-Shorafat (2013); Al-Sager (2017); Fakih (2007a, 2007b, 2011). There are also other studies conducted on wh-movement in Arabic dialects (e.g., Najrani Arabic, Fakih (2014); Al-hamami and Alfadly (2018); Hodeidi Arabic, Fakih (2015); Iraqi Arabic, Wahba (1991); Palestinian Arabic, Abu-Jarad (2003); Makkan Arabic, Bardeas (2005); Jordanian Arabic, Al-Momani and Al-Saiat, (2010); Emirati Arabic, Leung and Al-Eisaei (2011); Cairene Arabic, Al-Touny (2011)). Moreover, although their syntactic analyses attempted to offer some insight into the syntactic derivation of wh-movement, they could not offer a satisfactory account because they followed different approaches to syntactic analysis, and some provided only brief descriptive accounts.

The existing literature demonstrates that a few studies have been conducted on wh-movement in Najrani Arabic and in turn some accounts have been offered on the subject in question. However, none of these studies has explored the syntax of the derivation of wh-questions based on Chomsky's $(2001,2005,2013,2015)$ Phase approach and has attempted to present a satisfactory treatment of the topic under investigation. However, the present study aims to provide a unified analysis of the derivation of wh-questions in Najrani Arabic based on Chomsky's the phase model. The objective of the paper is to examine the derivation of wh-questions in Najrani Arabic and show the interaction between the Najrani Arabic data and Chomsky's Phase approach.

The topic of wh-questions in Najrani Arabic has been selected for study for the following reasons: (i) There is a need to provide a unified account of wh-questions in Najrani Arabic within Chomsky's Phase framework, (ii) The derivation of wh-questions in Najrani Arabic has not been studied in detail yet, and (iii) it is crucial to show how wh-questions in Najrani Arabic can be derived in VSO and SVO word orders and point out how the Najrani Arabic data can interact with Chomsky's Phase analysis.

Moreover, the methodology we have used is based on an analysis of the data on our topic collected from Najrani Arabic native speakers. It is, however, supplemented by the data obtained from certain literary work(s) in Arabic and certain literary work(s) in English as well as the linguistic literature on English. We have adopted the analysis presented in the Phase approach of Chomsky in order to show how it can be accessed to that of Najrani Arabic data.

The paper is organized as follows. Section 2 is a literature review on wh-movement in English and other languages. It surveys the previous accounts on wh-analyses in Standard 
Arabic. Section 3 explores the recent analyses of wh-movement in Najrani Arabic, shows the existing gap in such analyses and suggests the alternative approach based on Chomsky's Phase theory. Section 4 introduces the Phase approach and the Phase Impenetrability Condition. Section 5 discusses wh-questions in Najrani Arabic in VSO and SVO word orders and shows that VSO is the unmarked word order for the derivation of wh-questions. It also examines the interaction between the Najrani Arabic data and Chomsky's Phase approach and shows how wh-questions can be derived in minimalist syntax. Section 6 summarizes the findings of the study.

\section{Theoretical Background}

\subsection{Previous Analyses of Wh-questions in English and Other Languages}

By the advent of Chomsky's (1957) Syntactic Structures, the transformational generative analysis of wh-questions witnessed a radical shift, where Chomsky posited two transformational rules to derive interrogative constructions in English. Chomsky derived wh-questions in English by proposing a new optional transformation $T w$ and stressed that there must be an ordering of rules in order for these transformations to apply in the right manner. Furthermore, it has been observed that the Standard Theory and Extended Standard Theory of Chomsky in the 1970s have witnessed a crucial development in the syntactic derivation of wh-movement; generative syntacticians have proposed new rules, modifications and constraints. Bach (1971), for instance, proposed a universal rule of wh-question movement in English and indicated that wh- movement is always to the left, and not to the right, of the clause. Culicover (1976:72) observed that the earlier analyses of wh-questions in English and other languages were inadequate and did not provide a proper account of the issue at hand. Culicover showed that "there is an interaction in wh-questions between Inversion and the presence of the wh-word in sentence-initial position", (p.73). For Culicover, inversion takes place when a wh-word is placed sentence-initially. Besides, Culicover resorted to a transformation, which moves such wh-words to the initial position of the clause, and called it Fronting. Given this, Culicover assumed that "all of the wh- words share some deep structure marker in common" (p.74). Culicover proposed the following wh Fronting rule, demonstrated in terms of the marker wh, shown in (1).

\section{Wh Fronting $\mathrm{X}$ NP Y \\ $123 \longrightarrow 2+1 \varnothing 3$ \\ Condition: 2 dominates wh}

The proposed syntactic analyses, in the existing literature on transformational generative grammar, assumed that wh-questions contain an underlying abstract Q-morpheme in the interrogative deep structures, which occurs sentence-initially in interrogative deep structures; it is used as a condition on Inversion and wh-Fronting, and plays a role in the semantic interpretation of the sentence. Culicover (1976) criticized the presence of the Q-marker hypothesis and argued that "there does not appear to be any compelling purely syntactic evidence in favor of assuming the existence of this abstract marker, however", (p.76fn). 


\section{Macrothink}

On the other hand, in his seminal work on wh-movement, Chomsky (1977) provided an interesting generative account of how wh-questions could be derived in the syntax, explored how a wh-word moves to the sentence-initial position, and what it leaves behind after syntactic wh-movement. Moreover, as the universal syntactic theory developed, major changes and modifications followed in the 1980s. The major shift in standardizing the wh-movement analysis began by the advent of Chomsky's (1981) Government and Binding Theory; Chomsky (1981) suggested what is called "unbounded" (i.e. successive-cyclic) wh-movement in his analysis of wh-movement. Chomsky discussed how to interpret Move $\alpha$ in the case of movement from S to COMP and showed how the wh-phrase is assigned Case before wh-movement takes place. Besides, Chomsky (1981) stated that the trace (variable), left behind after movement, is co-indexed with the operator 'wh-word', which binds it. In his analysis of pro-drop languages, Chomsky (1981) emphasized that a wh-phrase in subject position is syntactically motivated to move to COMP position. Chomsky (1981) stressed that "wh-movement of the subject in pro-drop languages, which appears to violate the *[that- $t$ ] filter, is actually from the post-verbal rather than the subject position..." (p. 254). Furthermore, the third significant shift in the syntactic analysis of wh-questions in English and other languages in the world had been observed in Chomsky's (1986a) Barriers, where he incorporated the non-lexical elements C[omplemetizer] and I[nflection] into X-bar analysis of maximal projections, as shown in the basic structure of a clause in (2).

2.

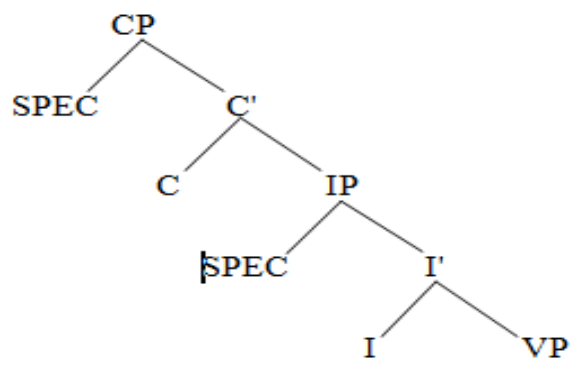

In the Barriers framework (1986a), Chomsky explained that the Spec of CP is equivalent to $\mathrm{S}^{\prime}$ in other systems. He proposed that the Spec of $\mathrm{CP}$ is a position where the moved wh-phrase should target in the course of syntactic derivation of a wh-word movement. He extended his analysis to show that the Spec of IP is the position for a subject DP. In his (1986a) Barriers framework, Chomsky proposed two types of movement: substitution and adjunction. It was in Chomsky's (1986a) Barriers that the incorporation of the functional categories (i.e., Spec-CP and Spec-IP) provided a neat account of the syntax of wh-question movement in the world languages and was considered as a valuable contribution in the history of morph-syntactic analyses of wh-movement.

Radford (1981) states that the existing rules (from pre-Chomskyan syntax) are not satisfactory, because they could not offer a satisfactory treatment for many interrogative constructions in a language. Given this, Radford posited a new level of structure (i.e. the underlying structure) and a new rule called Transformation (=movement rule), known as "WH-MOVEMENT," (p.146). Radford (1988) proposed an empty complementizer (C) in the 
Comp position responsible for the derivation of an S-structure by the operation of two movement rules: I-MOVEMENT and WH-MOVEMENT.

On the other hand, it has been observed that various syntactic analyses have been offered and several approaches have also been proposed with the aim of presenting a satisfactorily unified treatment of wh-questions in different languages across the world (Watanabe (1991); Cheng (1991, 1997); Aoun and Li (1993); Haegeman (1994); and Ouhalla (1996), among others.

In the Minimalist Program, Chomsky (1995) argued, following Watanabe's (1991) analysis of wh-movement, that there is no parametric difference with regard to wh-in-situ phenomenon. Given this, Chomsky (1995:199) reduced the differences between languages (for example the difference between English and Japanese) to "the internal morphology of the wh-phrases" (p. 199). Furthermore, Chomsky indicated that the raising of the wh-operator is ever overt, contrary to the principle of Procrastination, and assumed that the basic assumption of "economy of derivation" is that operators are driven by morphological necessity, since they are "last resort", to use Chomsky's (1995) terminology. Chomsky stated that, according to the minimalist assumptions, there are certain features that have to be checked in the licensing domain of a head, otherwise the derivation will crash. Therefore, the raising of a wh-operator to $[\mathrm{Spec}, \mathrm{CP}]$ must be motivated by such a requirement. Moreover, Chomsky assumes that the raising of a wh-operator to the $[\mathrm{Spec}, \mathrm{CP}]$ configuration is driven by the need for a morphological Q-feature to be licensed. What is really interesting in Chomsky's analysis of wh-questions is that in a simple interrogative clause in English, the head C (=COMP) contains an underlying abstract affixal question Q. He claims that in a language like English, the head $\mathrm{C}$ has a strong Q-feature, as does the operator that raises to it. It can be noted that the proposed operator feature, which Chomsky takes to be the Q- or wh-feature, is assumed to be present in the D-structure (i.e. at LF) of an interrogative clause, which in turn distinguishes itself from its declarative counterpart. Chomsky (1995) argues that "the operators raise for feature checking to the checking domain of $\mathrm{C}$ : [Spec, CP], or adjunction to Spec (absorption), thereby satisfying their scopal properties" (p. 199). Furthermore, Chomsky (1995) assumes, following Watanabe's (1991) analysis, that the Q-feature is strong in all languages, "the wh-operator feature is universally strong" (p. 199).

\subsection{Fakih's (2007, 2011) Minimalist Account of Wh-Questions in Standard Arabic}

Fakih $(2007,2011)$ explored the syntax of wh- and multiple wh-raising in Standard Arabic and English and pointed out the similarities and differences between both languages. He indicated that that many languages permit overt wh-movement to [Spec, $\mathrm{CP}$ ] to take place in overt syntax (like Standard Arabic and English), while other languages do not allow overt raising of wh-phrases (like Chinese and Japanese); in the latter type of languages, wh-raising to [Spec, CP] must undergo covert movement at LF, thus obeying the principle of Procrastination, as termed by Chomsky (1995). Based on Chomsky's (1995) minimalist analysis of wh-movement and feature checking in English, Fakih examined wh-movement in Standard Arabic question phrases extracted from subject and object positions of simple finite sentences and pointed out that Standard Arabic permits only question phrases derived with the normal VSO order, and not the SVO order. Furthermore, Fakih observes that the raising 
of a wh-operator in Standard Arabic to [Spec, CP] is highly motivated by the necessity for a morphological Q-feature (=wh-feature) to be checked in the licensing domain of [СР [Spec $\left[\mathrm{C}^{+} \mathrm{Q}\right]$...]]]. Fakih's (2011) analysis illustrated that the Standard Arabic question phrase originating in the subject/object position of a simple finite sentence undergoes an obligatory overt movement to [Spec, $\mathrm{CP}$ ] for feature licensing and that it cannot stay in-situ in overt syntax. Besides, he investigated how the Minimal Link Condition (MLC) works in the syntactic analysis of wh-questions words. The analysis demonstrated how the LF-representation can play a significant role in the minimalist syntax of multiple wh-words movement in Standard Arabic and English and how overt multiple wh-raising is allowed in some languages (the Slavic languages, for instance) while it is not at all permitted in languages like Standard Arabic and English.

Fakih (2007a, 2007b, 2011) assumed that in a simple interrogative clause of Standard Arabic, the head $\mathrm{C}$ has a strong feature of $\mathrm{Q}$ and that the question operator which raises to it (i.e. $\mathrm{C}$ ) has also a strong Q-feature that raises overtly for feature checking. He indicated that the wh-question word raising in Standard Arabic is overt, and not covert. He attributed this to the fact that the strong feature of Q the question word operator in Standard Arabic is motivated to raise overtly to license its own morphological features against that of the interrogative head $\mathrm{C}$ under the Spec-head agreement relation and in so doing it satisfies the feature of the head it raises to. He concluded that the question word movement in Standard Arabic is overt, since the raising of $\mathrm{F}_{\mathrm{Q}}$ (= wh-feature) to the checking domain of [Spec, Q] eliminates the strong feature of Q, as shown in (3) and (4).

3a.

$$
\begin{array}{lcc}
\mathrm{Q} \text { [IP yabni: } & \text { zayd-un } & \text { qasr-an }] \\
3 \mathrm{~m} \text {-sg-construct-pres. } & \text { Zaid-nom } & \text { palace-acc-indef. }
\end{array}
$$

$$
\begin{aligned}
& \text { [CP } \operatorname{man}\left[\mathrm{C}^{\prime}[+\mathrm{Q}][\mathrm{IP} \text { yabni: }\right. \\
& \text { who }
\end{aligned} \mathrm{t}_{\operatorname{man}} \begin{gathered}
\mathrm{qasr}-\mathrm{an} \text { ? }]] \\
\text { palace-acc-indef. }
\end{gathered}
$$

'Who constructs a palace?'

$$
\begin{aligned}
& \text { 4a. Q[IP ša:had - at hind - un rajul-an ?] } \\
& \text { see-pst-f.sg. Hind-nom man-indef.acc. } \\
& \text { b. [CP ma:ða: [C }[+Q] \text { [IP ša:had - at hind - un tma:ða: ?]] } \\
& \text { what see-pst-f.sg. Hind-nom. } \\
& \text { 'What did Hind see } t_{\text {what? }} \text { ? }
\end{aligned}
$$

According to Fakih, the sentence in ( $3 b$ ) shows that the subject wh-word has been moved obligatorily from the subject position to the sentence -initial position in overt syntax and the same syntactic operation takes place with the moved object wh-phrase in (4b).

\subsection{Recent Accounts of Wh-questions in Standard Arabic}

In a recent study conducted on wh-movement in Modern Standard Arabic, Alotaibi (2013) indicates that "the SVO order is formed via base generation and not via movement. Empirical evidence shows that the A'-movement effects in the SVO order" (p.7). Alotaibi stressed that 
Modern Standard Arabic has two word orders; VSO and SVO. Alotaibi (2013) is with the view that wh-movement in these two word orders applies only to the unmarked VSO word order, and not to the SVO word order. Alotaibi argues that "A problem arises when the non-subject wh-phrases move over the SV order," (p.1).

On the other hand, Al-Shorafat (2013) explores the syntax of wh-questions in Standard Arabic within a phase-based approach advocated in Chomsky (2006) and demonstrates that agreement and movement obey the principles of the phase theory. Al-Shorafat (2013) supports the view that the derivation of wh-questions in Standard Arabic can be observed in the unmarked VSO word order.

Al-Sager (2017) examined the structure of wh-questions in Modern Standard Arabic on the basis of the Minimalist Program (2001, 2008, 2013, 2015) and the Cartography approach by Rizzi (1997, 2001). Al-Sager attempted to combine Chomsky's approach and Rizzi's approach) into one approach; Al-Sager's analysis addressed nominal wh-questions in simple and complex clauses, adverbial wh-questions and resumptive strategies in wh-clauses. Despite the fact that Al-sager's account of wh-questions is recent and informative; it did not show clearly the interaction between wh-questions in Standard Arabic and Chomsky's Phrase model. It did not address in detail how wh-questions in Standard Arabic can be derived morpho-syntactically.

However, the current study seeks to fill this gap and attempts to provide a satisfactory account on how wh-questions can be derived in Najrani Arabic VSO word order and how they can be represented syntactically on a clause structure based on Chomsky's (2001, 20115, 2013, 2015) Phase approach.

\subsection{The Syntax of Wh-movement in Arabic Dialects}

It can be observed in the existing literature that, during the last three decades, the syntactic analysis of wh-questions in modern Arabic dialects has received much considerable attention in the syntactic accounts of Western and Arab linguists and syntacticians, who have addressed different issues of wh-questions in Arabic dialects and in turn have attempted to provide various treatments on the subject within different frameworks in an attempt to present a unified analysis. Let us summarize the major syntactic analyses on the subject under study into three views. (i) There are some Arabic varieties which permit optional wh-movement; either they permit the wh-phrase to move to [Spec, CP] at S-structure (e.g., Iraqi Arabic, Wahba (1991); Palestinian Arabic, Abu-Jarad (2003); Makkan Arabic, Bardeas (2005); Jordanian Arabic, Al-Momani and Al-Saiat, (2010); Emirati Arabic, Leung and Al-Eisaei (2011); Cairene Arabic, Al-Touny (2011)), or remain in-situ (e.g., Iraqi Arabic, Wahba, (1991); Palestinian Arabic, Abu-Jarad (2003); Makkan Arabic, Bardeas (2005); Jordanian Arabic, Al-Momani and Al-Saiat (2010); Cairene Arabic, Al-Touny (2011)). This line of analysis was advocated by many linguists including Aoun and Li (1993), Cheng (1991), Denham (2000) and Pesetesky (1987); they viewed languages such as French, Egyptian Arabic, Iraqi Arabic, Babine language, Bahasa Indonesia, and Palauan as optional languages. (ii) There are, however, other Arabic dialects which do not allow the wh-phrase to move overtly; such Arabic varieties are viewed as wh-in-situ languages (e.g., Egyptian 
Arabic, Cheng (1991, 2000), Lassadi (2003), Sultan (2010) and Yassin (2013); Makkan Arabic, Abu-Sulaiman (2007)). (iii) There are other Arabic dialects which permit the wh-question word to move obligatorily to [Spec, CP] in overt syntax (e.g., Moroccan Arabic, Nouhi (1996); Jordanian Arabic, Yassin (2013); Najran and Hodeidi Arabic, Fakih 2014, 2015, 2016, 2017)).

A closer look at analyses of the Arab syntacticians and grammarians reveal that different approaches have been suggested with the aim of presenting a unified treatment of wh-questions in Arabic dialects. Wahba (1984) indicates that wh-scope licensing in Egyptian Arabic takes place via movement: covert movement in the case of in-situ wh-questions, and overt movement in the case of ex-in-situ wh-questions. Given this, Sultan (2010), however, adopts a different position in his analysis of wh-scope licensing in Egyptian Arabic; he stresses that wh-scope does not take place via movement, but rather via the mechanism of unselective binding in the sense of Pesetesky (1987). What is really interesting in Sultan's (2010) analysis is that it is supported by empirical evidence from island-insensitivity and intervention effects against a systematic movement analysis of wh-questions in Egyptian Arabic, as assumed in Wahba's (1984). Given the other accounts for other Arabic dialects (e.g., Aoun and Choueiri 1998 for Lebanese Arabic and Shlonsky 2002 for Palestinian Arabic), it can be observed that Sultan (2010) points out that "fronting of wh-argument in Egyptian Arabic is not strictly prohibited" (pp.18-19).

Moreover, it has been observed that many modern spoken Arabic dialects use more than one strategy in the formation of wh-questions (as in Iraqi Arabic (Ouhallah (1996), Simpson (2000) and Wahba (1991)), Lebanese Arabic (Aoun, Benmamoun and Choueiri (2010), and Aoun and Li (2003)), Egyptian Arabic (Cheng (1991), Sultan (2009) and Wahba (1984)) and Jordanian Arabic (Al-Moman (2010). In this regard, Abdel Razaq (2011) explores the typological variation in wh-constructions in Iraqi, Lebanese and Jordanian Arabic and asserts that in spite of the fact that such Arabic dialects share many morpho-syntactic properties, there are still some differences in the strategy used in the derivation of of wh-questions. Furthermore, Abu-Jarad (2008) examines the typology of wh-movement in Palestinian Arabic and argues that the wh-operators in Palestinian Arabic function in two different ways based on the type of wh-operator, whether it is a wh-argument or a wh-adjunct. According to Abu-Jarad's analysis, wh-arguments do not have syntactic movement (as in Egyptian Arabic) while wh-adjuncts undergo raising to the matrix Comp (as in Araqi Arabic). In their syntactic analysis of wh-questions, Leung and Al-Eisaei (2011) pointed out two major types of wh-constructions in Emirati Arabic (i.e., wh-fronting and wh-cleft) and asserted that these structures are construed by independent strategies; wh-fronting is a wh-construction, whereas wh-cleft is a non-movement construction. A recent study conducted by Yassin (2013) on wh-movement in Jordanian Arabic (JA) and Egyptian Arabic (EA) it reveals that the former (i.e., JA) moves the wh-phrase, whereas the latter leaves it in-situ.

In his recent study on wh-questions, Fakih (2015) examines the syntax of wh-questions in Hodeidi Arabic within Chomsky's (2001, 2005, 2006) Phase-Based approach and shows that question phrase movement in Hodeidi Arabic is an obligatorily syntactic movement, where the wh-phrase undergoes fronting to the left periphery of the clause. Fakih explores the 
interaction between wh-questions in Hodeidi Arabic and the Phase-Based analysis and indicates that the minimalist analysis proposed in Hodeidi Arabic is a further support to Chomsky's Phase-Based approach. Fakih observes that Hodeidi Arabic obeys the Phase Impenetrability Condition proposed in Chomsky (2001). Fakih illustrates that when all syntactic operations in a given phase have been completed, the complement or the domain of the phase becomes impenetrable to any further syntactic operations; this takes place when the structure is sent to the interface levels for interpretation. Furthermore, Fakih states that, in the syntactic derivation of subject and object wh-questions in Hodeidi Arabic, both the subject and object wh-words have to pass through certain phases till they reach [Spec, $\mathrm{CP}]$; once the derivation is completed, the head $\mathrm{C}$ and its specifier (the subject/object wh-word) undergo transfer to the PF and LF levels for proper representations, and consequently, the clause is interpreted as an interrogative in the syntax.

\section{Recent Analyses of Wh-movement in Najrani Arabic}

\subsection{Wh-movement in Najrani Arabic (2018): Al-hamami and Al-fadly (2018)}

Al-hamami and Al-fadly (2018) attempted to offer an idiosyncratic investigation of wh-movement in Najran Arabic based on the earlier version of minimalism. They indicated that wh-phrases in Najrani Arabic have the option either to move the sentence-initial position or remain in-situ. They discussed wh-raising in simple and embedded clauses. However, their analysis was only based on a brief descriptive manner and did not provide a satisfactorily unified account of the derivation of wh-questions based on the recent developments in Chomsky's $(2001,2005,2013,2015)$ Phase model. Their analysis is not convincing and lacks the explanatory approach and illustrative tree-diagrams to show the internal relationship between the constituents of the interrogative clause structure of Najran Arabic; it did not also show clearly the interaction between Najrani data and that of Chomsky's Phase theory.

However, the present study will fill this gap and will show the interaction between the syntactic derivation of wh-questions in Najrani Arabica and the assumptions of Chomsky's recent analyses assumed in the Phase model.

\subsection{Fakih's (2014) Analysis of Subject Wh-movement in Najrani Arabic}

The study seeks to show whether it is possible for the subject-wh to move overtly from [Spec, VP] to [Spec, IP] at PF and then to [Spec, CP] at LF because of its weak [wh] feature. In his analysis of wh-movement in Najrani Arabic, Fakih (2014) assumes that illi 'that' is viewed as a complementizer which heads the head $\mathrm{C}$ position of CP. Fakih, however, shows that this line of argument has been found to be unsystematic because it fails to provide a satisfactory account on the subject under discussion when compared to Focus movement analysis presented as an alternative to wh-movement in Najrani Arabic. Furthermore, following Focus movement analysis in Rizzi (1997, 2001) and Gad (2011), Fakih (2014) proposes an alternative analysis in which he assumes that the complementizer illi is viewed as a relative pronoun and heads the Focus projection. The analysis reveals that the subject-wh word moves overtly to [Spec, Focus] for feature checking considerations. Following Rizzi's (1997, 2001) assumptions, Fakih argues that the subject wh-movement is triggered by the strong Focus 
feature on the head illi, which occupies the FocusP projection; this movement takes place before Spell-Out.

Fakih (2014) demonstrates that "the structure [wh-phrase+illi+VP] occurs in a Focus projection headed by illi. It has been suggested that subject wh-movement in Najrani Arabic is triggered by a feature other than the wh-feature; hence, wh-phrases do not occur in the CP projection, but rather in [Spec, Focus]; the head $\mathrm{C}$ is occupied by the invariant relative pronoun illi" (p.26). Fakih further states "When illi occupies the head C position it creates the FocusP projection which is the proper licensing domain for the wh-phrase in [Spec, Focus]" (p.26). Accordingly, Fakih proposes that it is the strong Focus feature that motivates movement to take place before Spell-Out. Given this, the subject wh-word raises overtly to [Spec, Focus] for feature checking considerations. Besides, "Focus-movement takes place for the Focus-feature of the wh-phrase to be licensed against the strong Focus feature of illi which heads the FocusP projection, so the wh-phrase is moved to [Spec, FocusP]. Thus, Focus movement analysis has shown to be superior to that of [Spec, CP] analysis because it provides a unified treatment of subject wh-movement in Najrani Arabic in a systematic manner" (p.26).

It can be observed that Fakih's (2014) syntactic analysis of subject wh-movement is based on Focus movement analysis outlined in Rizzi (1997, 2001). However, the present study will take a different position from Fakih (2014); it will adopt a phase-based approach ' $h$ advocated in Chomsky $(2001,2006,20013,2015)$ in analyzing the syntax of the derivation of wh-questions in Najrani Arabic.

\subsection{The Existing Gap in the Current Literature on Wh-questions in Najrani Arabic}

It can be observed in the existing literature that a few studies have been conducted on wh-movement in Najrani Arabic and in turn, some analyses have been offered on the subject under investigation. However, none of these studies explored the syntax of the derivation of wh-questions based on Chomsky's (2001, 2005, 2013, 2015) Phase approach and attempted to present a satisfactorily unified treatment of the derivation of wh-questions in Najrani Arabic. For instance, although Al-sager's (2017) analysis of wh-questions is recently conducted and seems informative, it does not address clearly the interaction between wh-questions in Standard Arabic and Chomsky's Phrase model. That is, it does not show, in detail, how wh-questions in Standard Arabic can be derived morpho-syntactically and which word order can be used to derive such interrogatives in the language. However, the current study on wh-questions in Najrani Arabic seeks to fill this gap and attempts to provide a satisfactory account on how wh-questions can be derived in Najrani Arabic VSO word order and how they can be represented syntactically on a clause structure based on Chomsky's (2001, 20115,2013, 2015) Phase approach.

The gap that exists in Al-hamami and Al-fadly (2018) is that their analysis is based only on a brief descriptive manner and, hence, does not provide a satisfactorily unified analysis of the derivation of Najrani Arabic wh-movement based on the recent developments in Chomsky's (2001, 2005, 2013, 2015) Phase framework. Their argument of wh-movement is not convincing and lacks the explanatory approach based on illustrative tree-diagrams to show 
the internal relationship between the constituents of wh-questions on the clause structure of Najran Arabic. In other words, it does not address the interaction between wh-questions in Najrani Arabic and that of Chomsky's Phase theory. However, the present study will fill this gap and will show clearly the interaction between the syntactic derivation of wh-questions in Najrani Arabic and Chomsky's recent analyses advocated in the Phase approach.

It can be observed that Fakih's (2014) syntactic analysis of subject wh-movement is based on Focus movement analysis outlined in Rizzi (1997, 2001). However, the present study will take a different position from Fakih (2014); it will adopt a phase-based approach advocated in Chomsky $(2001,2006,20013,2015)$ in analyzing wh-questions in Najrani Arabic. The objective of this study is to fill the gap that exists in the previous studies on Najrani Arabic wh-questions and present a satisfactory account on the subject under study.

\subsection{Wh-questions in Minimalism: Chomsky's (1995, 2000) Wh-movement Analysis}

A closer look at the recent developments of linguistic theory illustrates that Chomsky (1995) assumes that wh-movement is triggered by a strong operator feature of the functional C-head. Chomsky (1995) assumes that "the natural assumption is that $\mathrm{C}$ may have an operator feature and that this feature is a morphological property of such operators as wh-. For an appropriate C, the operators raise for feature checking to the checking domain of C: [Spec, CP]" (p. 199), thereby satisfying their scopal properties. Chomsky denotes that if the operator feature on the head $\mathrm{C}$ is strong, movement is overt (as in English), and if the operator feature is, however, weak, then wh-movement is delayed until LF (as in Chinese). Hence, the trigger of movement, whether it is overt or covert, is always located on a target. Based on Watanabe (1991), Chomsky (1995) assumes that the Q-feature is strong in all languages: "the wh-operator feature is universally strong" (p.199). The following examples of Chomsky (1995:293) demonstrate the point.

5a. Q[IP who will fix the car]

b. Q[IP John will fix what]

c. Q[IP John will fix the car how (why)]

A closer look at the sentences in (5) reveals a radical shift in the syntactic derivation of wh-questions in English and other languages in the world. Chomsky (1995) states that if an interrogative structure contains an overt wh-phrase, whether it is in the subject, object or adjunct position, the wh-feature adjoins covertly to Q position. Chomsky confirms that (5a) is interpreted as a wh-question, though it has overt syntactic properties of IP, (5b) gives the interpretation 'what will John fix', and (5c) is interpreted as 'how (why) will John fix the car'. Based on Chomsky's (1995) analysis, the wh-phrase in (5) raises to [Spec, CP] where it has to be checked "by Q-feature of the complementizer C, not of the latter being licensed by the raised wh-phrase" (p. 259).

Moreover, Chomsky (2000) has made some modifications in the assumptions of the Minimalist Inquiry in order to refine some weaknesses in the proposal. Chomsky (2000) argues that wh-movement in this framework has the following technique: "the wh-phrase has 
an uninterpretable feature [wh-] and an interpretable feature [Q], which matches the uninterpretable probe [Q] of a complementizer" (p. 44). Chomsky stresses that the uninterpretable probe [Q] on the head $\mathrm{C}$ searches for the goal, a wh-phrase, and once the probe $(\mathrm{P})$ finds the goal $(\mathrm{G})$, the uninterpretable features (on both probe, F[Q], and goal, $\mathrm{F}[w h])$ are checked and deleted in the syntax. Given this, feature checking is achieved by, what Chomsky calls, the syntactic operation Agree; it is in this operation that no movement is involved. Chomsky (2000) observes that the uninterpretable [wh-] feature of a wh-phrase is "analogous to structural Case for nouns" (p. 21) and, as a result, it does not have an independent status, but is a reflex of certain morpho-syntactic properties of Q. Chomsky points out that it is in this framework that the head $\mathrm{C}$ has only an uninterpretable $\mathrm{Q}$ feature; this uninterpretable probe [Q] on the head $\mathrm{C}$ cannot be an operator, as it is checked and deleted in the syntax. The interpretable $[+\mathrm{Q}]$ feature, which is presumably a question operator, is assigned to a wh-word in the course of syntactic derivation of a wh-question. Chomsky (2000) proposes the presence of an EPP-feature on the head C head in an attempt to account for the displacement of a wh-phrase, since uninterpretable features are checked without triggering movement in this modified framework. Chomsky assumes that the EPP-feature on the head $\mathrm{C}$ is similar to the EPP-feature of the head $\mathrm{T}$; this requires the [Spec, $\mathrm{CP}$ ] configuration to be filled which results in the displacement of a wh-phrase.

\section{Introducing the Phase Approach and the Phase Impenetrability Condition}

A closer look at the minimalist syntax reveals that Chomsky (2000, 2001, 2005a, 2005b, 2006, 2013, 2015) introduced three syntactic operations: MERGE (or External Merge), MOVE (or Internal Merge), and AGREE; each one of these three operations applies in specific configurations. According to Chomsky's analysis, Merge and Move give rise to multiple specifiers in minimalist syntax, if two syntactic objects target the specifier position of the same head. MERGE is the most basic operation in this approach. Fakih (2015) and Bardeas (2005) indicate that in Merge two syntactic objects $a$ and $b$ form another syntactic object $\{a, b\}$. That is, it takes two objects $(\alpha$ and $\beta$ ) and merges them into an unordered set with a label (either $\alpha$ or $\beta$, in this case $\alpha$ ). The label identifies the properties of the phase in (6).

\section{(6). Merge $(\alpha, \beta) \rightarrow\{\alpha,\{\alpha, \beta\}\}$}

Given (6), Chomsky stresses that the new object inherits the properties of one of the two merged elements, e.g. $a$. If $a$ passes its properties to the newly formed object, $a$ is considered the head of the pair, and it is also the label of the new object. MERGE is always a binary operation; only two syntactic objects can be merged at a time. It is also a recursive operation. An object formed by MERGE can be one of two elements joined by another instance of the same operation, Bardeas (2005). Moreover, MERGE is subject to the Extension Condition, which states that syntactic operations are applied only to the root, Chomsky (1995). Furthermore, MOVE is the case of Internal Merge, where one of the elements merged comes from inside the other one. Moreover, Chomsky (2000) argues that the operation AGREE establishes a relation (agreement, Case-checking) between LI $\alpha$ and a feature F in some restricted search space (its domain). That is, it establishes the relationship between an 
uninterpretable feature on a probe and a target in the probe's c-command domain. Chomsky states that the feature that needs to be checked is not strong, and consequently, it does not need to be licensed in a Spec-head configuration. Given that MOVE is a costly operation, the target need not rise, and the feature is checked by the primitive operation AGREE only. However, for AGREE to apply in the syntax, Chomsky (1999) sees that both the probe and the goal must be active, for example, they must have uninterpretable features to be checked and AGREE 'deactivates' them both by checking these features, Fakih (2015); Bardeas (2005).

The origin of the term "phase", as a syntactic domain, goes back to work by Chomsky in (1998) where he states that a simple sentence is often decomposed into two phases: CP and $\mathrm{vP}$, categories that are propositional phases. Chomsky proposes that $\mathrm{CP}$ and $\mathrm{v} * \mathrm{P}$ are phases: he assumes that $\mathrm{CP}$ represents a complete complex including its force marker (indicative, interrogative...etc.) and $\mathrm{vP}$ represents a complete thematic complex with an external argument, a subject DP. Chomsky $(2001,2005,2008)$ indicates that $C$ and $v$ are phase heads and those syntactic operations involve an agreement relation between a probe $\mathrm{P}$ and a local goal G. According to Chomsky's minimalist analysis, C, T and v are probes and that merger operations apply before any probing can take place. Chomsky maintains that a TP, within a $\mathrm{CP}$ domain, is a complete clause while infinitival embedded clauses, lacking CPs, are taken to be defective TP clauses. For Chomsky, defective TPs and vPs are not phases for the reason that they do not have an external thematic argument.

On the other hand, Chomsky $(2001,2005,2006)$ points out that movement of a constituent out of a phase is only allowed if the constituent has first moved to the left edge of the phase. This can be observed in analysis assumed in the "Phase Impenetrability Condition", to use Chomsky's term. It has been assumed in the Phase model that only the vP in transitive and unergative verbs constitute phases whereas the $\mathrm{vP}$ in passives and unaccusative verbs are not phases. The recent syntactic developments in minimalist analysis in Chomsky (2000, 2001, 2005a, 2005b, and 2006, 2013, 2015) reveal that 'phases' are the stages in the derivation, or nodes in the phrase marker, where the structure is transferred to the interface levels, and as a result it becomes no longer available for further syntactic operations.

Given Chomsky's $(2008,2013,2015)$ assumptions that the phases are CP and $\mathrm{v}^{*} \mathrm{P}$, one can observe that once $\mathrm{v} * \mathrm{P}$ is built up in the syntax, the structure inside $\mathrm{v} * \mathrm{P}$ (i.e., the $\mathrm{v} * \mathrm{P}$ domain) is transferred to the interface levels and is no longer available for any further syntactic operations such as MOVE or AGREE triggered by an uninterpretable feature on a probe (i.e., I or C), Fakih (2015); Bardeas (2005). According to Chomsky, the only exceptions are the head of the immediately lower phase and the syntactic objects on its edge: either its specifier or an element adjoined to it. Chomsky $(2000,2001)$ introduces the Phase Impenetrability Condition and argues that "in phase $a$ with head $H$, the domain of $H$ is not accessible to operations outside $a$, only $H$ and its edge are accessible to such operations," (108). This means that when all syntactic operations in a given phase have been completed in the syntax, the complement of the phase head becomes impenetrable to further syntactic operations, Chomsky (2001) terms this as the Phase Impenetrability Condition. According to Chomsky, the reason why the complement or the domain of the phase becomes impenetrable can be 
attributed to the domain that undergoes transfer simultaneously to the phonological and semantic components that must be assigned the appropriate representations.

In the following section, however, we explore the syntax of the derivation of wh-questions in Najrani Arabic and attempt to account for the interaction between the Najrani data and the Phase approach of Chomsky (2001, 2005, 2008, 2013, 2015).

\section{The Analysis of Wh-questions in Najrani Arabic}

\subsection{An Overview of Najrani Arabic: The Word Order and Clause Structure}

Modern Standard Arabic has many varieties spoken across the Arab world. Not only this, there also sub-varieties of these Arabic spoken varieties within the same region; in each Arab state there are different spoken varieties. These varieties differ from each other in the word order, vocabulary, verb morphology, semantic variation, among other things. However, in spite of all these differences, Arab speakers can manage to understand each other when they communicate with each other. However, the Arabic varieties commonly spoken in the Arabian Peninsula are observed to be the most standardized dialects in the Arab world because they share a lot of morpho-syntactic and semantic features of Standard Arabic; the reason behind this is that the Arabian Peninsula is the origin of Classical Arabic and the place of the Prophet Mohammad, peace be upon him.

Furthermore, Najrani Arabic is spoken the Southern region of the Kingdom of Saudi Arabia, an area that has hundreds of thousands of people. According to the 2008 census, the population of the Najran region is more than 700,000 people with a land survey of 360,000 square kilometers. It should be mentioned that Najrani Arabic shares many morpho-syntactic and semantic properties with Standard Arabic; this can be observed in the word order and clause structure of Najrani Arabic. Besides, it has a rich verb inflectional paradigm, which distinguishes its verb morphology from other Arabic varieties; this can be realized in its word order and rich verb inflection. A closer look at the Najrani Arabic clause structure shows that it exhibits two word order variations: VSO and SVO. It should be noted that the most common word order is the SVO because it is commonly used in daily life situations in the Najran region. The VSO word order, on the other hand, is also used in Najrani Arabic but it is not commonly used as the SVO order. Like Standard Arabic, the SVO word order exhibits full agreement between the subject NP of the clause structure with the verb in person, gender and number. This can be demonstrated in (7) and (8) below. 


\begin{tabular}{|c|c|c|c|}
\hline 7a. & $\begin{array}{l}\text { al-bint } \\
\text { the-girl.nom } \\
\text { 'The girl i }\end{array}$ & $\begin{array}{l}\text { ta-ktub risa } \\
\text { AGR marker.write(pres.f.sg) } 1 \\
\text { is writing a letter.' }\end{array}$ & $\begin{array}{l}\text { saalah } \\
\text { letter-acc.indef }\end{array}$ \\
\hline b. & $\begin{array}{l}\text { *al-bint } \\
\text { the-girl.nom }\end{array}$ & $\begin{array}{l}\text { a-ktub } \\
\text { AGR marker. write(pres.f.sg) }\end{array}$ & $\begin{array}{l}\text { risaalah } \\
\text { letter-acc.indef }\end{array}$ \\
\hline c. & $\begin{array}{l}\text { al-Siyaal } \\
\text { the-boy.nom } \\
\text { 'The boy }\end{array}$ & $\begin{array}{l}\text { ya-ktub } \\
\text { AGR marker.write(pres.m.sg) } \\
\text { is writing a letter.' }\end{array}$ & $\begin{array}{l}\text { risaalah } \\
\text { letter-acc.indef }\end{array}$ \\
\hline d. & $\begin{array}{l}\text { *al-Siyaal } \\
\text { the-boy.nom }\end{array}$ & $\begin{array}{l}\text { ta-ktub } \\
\text { AGR marker.write(pres.m.sg) }\end{array}$ & $\begin{array}{l}\text { risaalah } \\
\text { letter-acc.indef }\end{array}$ \\
\hline 8a. & $\begin{array}{l}\text { al-banaat } \\
\text { the-girls.nom } \\
\text { 'The girls }\end{array}$ & $\begin{array}{l}\text { ya-ktub-uun } \\
\text { AGR marker.write(pres.f.pl) } \\
\text { are writing a letter.' }\end{array}$ & $\begin{array}{l}\text { risaalah } \\
\text { letter-acc.indef }\end{array}$ \\
\hline b. & $\begin{array}{l}\text { al-Siyaal. } \\
\text { the-boys.nom }\end{array}$ & $\begin{array}{l}\text { ya-ktub-uun } \\
\text { AGR marker.write(pres.m.pl) }\end{array}$ & $\begin{array}{l}\text { risaalah } \\
\text { letter-acc.indef }\end{array}$ \\
\hline
\end{tabular}

From the sentences in (7) and (8), it can be observed that there is full agreement between the subject and the verb in the three phi-features (i.e., person, gender and number). The agreement features are clearly marked on the verb morphology in Najrani Arabic. Furthermore, the reason why the structures in (7b) and (7d) are ungrammatical can be attributed to the fact that the verb morphology lacks the agreement marker that reflects the morpho-syntactic harmony between the subject NP and the verb. On the other hand, the VSO word order can be illustrated below in (9).

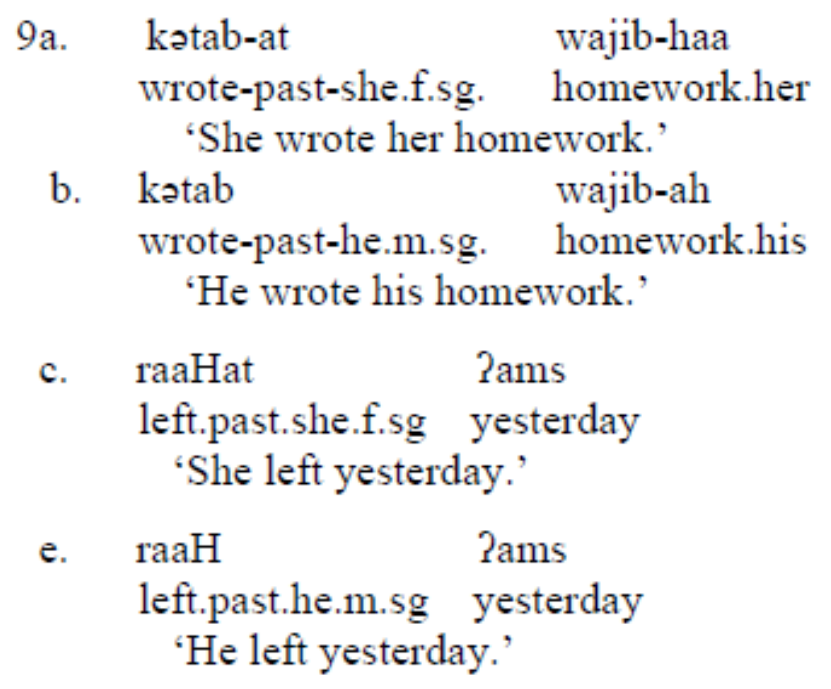

It can be noted in the sentences in (9) that the VSO order exhibits partial agreement in gender; there is no person and number agreement. The interesting observation about the VSO order in Najrani Arabic is that the subject NP can be recovered from the verb morphology. That is, the richness of the verb inflection determines clearly the identity of the subject gender; the 


\section{Macrothink}

International Journal of Linguistics

ISSN 1948-5425

2019, Vol. 11, No. 5

agreement marker on the verb spells out the gender identity of the subject and shows whether it is a masculine or feminine NP.

What is really interesting in Najrani Arabic is that wh-questions can be derived in the VSO word order. The next sections capitalize on the syntactic derivation of wh-questions in Najrani Arabic and account for the interaction between the Phase theory and the data in Najrani Arabic interrogatives.

\subsection{The Syntax of Derivation of Wh-questions in Najrani Arabic}

Before discussing how to account for wh-questions in Najrani Arabic within Chomsky's (2001, 2005, 2008, 2013, 2015) Phase-based approach, let us first examine how wh-questions can be derived morpho-syntactically in the permissible word order in Najrani Arabic syntax. First we analyze the derivation of wh-questions in VSO word order and then the derivation of wh-questions in SVO word order. It should be mentioned that there are seven wh-question words/phrases in Najrani Arabic: man 'who', aish/waysh 'what', ayy 'which', liih 'why', wayn 'where', kiif 'how', and mota 'when'. Concerning the object wh-word aish/waysh 'what', the majority of the native speakers on Najrani Arabic confirm that both aish and waysh have the same syntactic and semantic function and can be used interchangeably. However, some native speakers assert that waysh 'what' is used commonly by the elderly people and that the young native speakers tend to use aish 'what'.

\subsubsection{The Derivation of Wh-questions in VSO Word Order}

It has been mentioned in the preceding sections that Najrani Arabic displays VSO and SVO word orders. The question that can be posed here is: Can wh-questions be derived in VSO or SVO word orders or both? The objective is to explore wh-questions and word order derivation in Najran Arabic and provide a unified account of the issue at hand. First we discuss wh-question extraction from argument (subject and object) positions and then examine wh-question extraction from non-argument (adverbial) positions in Najrani Arabic. Let us investigate how wh-questions behave in the syntactic analysis of Najrani Arabic grammar in (10) and (11) below.

Wh-question extraction from argument position 


\section{MInstitute"}

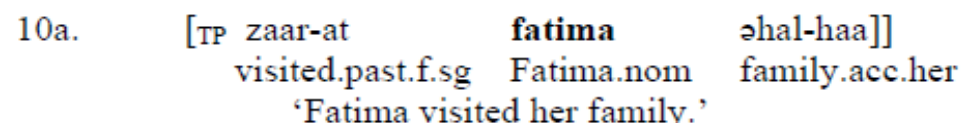

$$
\begin{aligned}
& \text { b. }[\mathrm{CP} \text { [C [TP zaar-at man shal-haa }] \\
& \text { visited.past.f.sg who family.acc.her } \\
& \begin{array}{c}
\text { c. } \quad[\mathrm{CP} \text { man } \\
\text { who }
\end{array} \begin{array}{c}
{[\mathrm{C}[\mathrm{TP} \text { zaar-at }} \\
\text { visited.past.f.sg } \\
\text { 'Who visited her family?' }
\end{array} \\
& \begin{array}{llll}
\text { 11a. } \quad[\text { [T } & \text { ketab } & \text { həssain } & \text { khitaab] } \\
\text { wrote.m.sg } & \text { Hussain.nom } & \text { letter.acc.indef }
\end{array} \\
& \text { 'Hussain wrote a letter.' } \\
& \text { b. }[\mathrm{CP} \quad[\mathrm{C} \text { [TP katab hassain aish }] \\
& \text { wrote.m.sg Hussain.nom what } \\
& \text { c. [CP aish [C [TP kətab hessain } \\
& \text { where wrote.m.sg Hussain.nom } \\
& \text { 'What did Hussain write } t_{\text {what }} \text { ?' }
\end{aligned}
$$

The sentences in (10a) and (11a) are declarative and are used in VSO word order. It can be observed that (10b) and (11b) show the process of the derivation of wh-questions at the deep structure from both the subject position (10b) and object position (11b), consecutively; these subject and object positions are argument positions, assigned (nominative and accusative) case and theta roles. Furthermore, in (10b) the subject wh-question man 'who' moves from the subject argument position to the sentence-initial position (i.e., Spec-CP position) to derive a wh-question and then satisfy the Edge feature on the interrogative phase head $\mathrm{C}$, given Chomsky's (2001,2005, 2008, 2013, 2015) Phase approach. Moreover, the object wh-question in (11b) aish 'what' raises from the object argument position to the clause-initial periphery to form a wh-question and satisfy the Edge feature on the interrogative phase head $\mathrm{C}$ of CP. Furthermore, it can be noted that VSO word order is the unmarked order for the normal derivation of wh-questions in Najrani Arabic.

Moreover, it can be observed that, in Najrani Arabic VSO, the subject does not move to Spec-TP. We assume that the head T(ense) in Najrani Arabic does not have an EPP feature. This entails that the subject NP does not raise to Spec-TP because it lacks the EPP feature, the latter attracts movement of the former. This means that it is the verb that moves higher up to the head T of TP in the clause structure for feature valuation, while the subject NP remains in-situ in Spec-vP in Najrani Arabic VSO word order. The other interesting observation is that wh-movement in Najrani Arabic is obligatory and takes place in overt syntax. This can be illustrated in (12) below.

$$
\begin{aligned}
& \text { 12a. } *[\mathrm{CP} \text { [C [TP zaar-at man shal-haa }] \\
& \text { visited.past.f.sg who family.acc.her }
\end{aligned}
$$

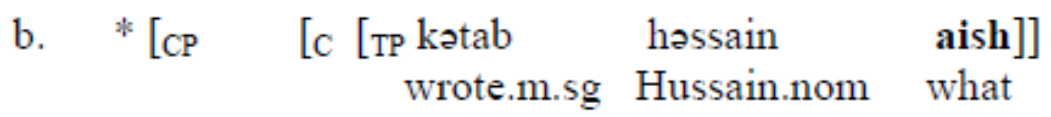




\section{Macrothink}

The ungrammaticality of the sentences in (12) can be attributed to the fact that the subject and object wh-question words cannot stay in-situ in overt syntax. That is, the wh-words in (12) have to raise from their original positions to the clause-initial positions of $\mathrm{CP}$ in order to satisfy the Edge feature on the phase head $\mathrm{C}$ of CP. We will address this issue in detail in the next sections.

\section{Wh-question extraction from non-argument position}

The preceding sub-section examined wh-question extraction from argument positions. This sub-section, however, analyzes wh-question movement from non-argument (adverbial) positions to show whether adverbial wh-movement is allowed in VSO order in Najrani Arabic. This can be shown in (13), (14), and (15).

$$
\begin{aligned}
& \text { 13a. [тр raaH al-walad el-souq } \\
& \text { went the.boy.nom the.market.acc } \\
& \text { 'The boy went to the market.' } \\
& \text { b. [CP [c [TP raaH al-walad wayn }]] \\
& \text { went the.boy.nom where } \\
& \text { c. [CP wayn [C [TP raaH al-walad } \left.\boldsymbol{t}_{\text {wayn }} \text { ?] }\right] \\
& \text { where went the.boy.nom } \\
& \text { 'Where did the boy go?' } \\
& \text { 14a. [TP saafar Sili al-baareHah } \\
& \text { travelled Alinom last night } \\
& \text { 'Ali travelled last night.' } \\
& \text { b. }[\mathrm{CP} \quad[\mathrm{c} \text { [TP saafar Sili məta }]] \\
& \text { travelled Alinom when } \\
& \text { c. [CP məta [c [TP saafar Sili } \boldsymbol{t}_{\text {mota }} \text { ?] } \\
& \text { when travelled Alinom } \\
& \begin{array}{c}
\text { 15a [TP raaH saeed el-souq } \quad \text { yashtari sayyarah } \\
\text { went Saeed.nom the.market.acc buy } \\
\text { 'Saeed went to the market to buy a car.' }
\end{array}
\end{aligned}
$$

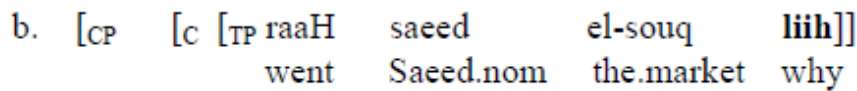

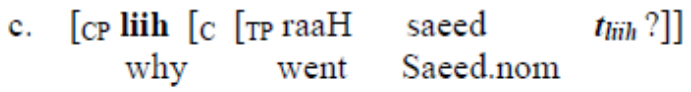

$$
\begin{aligned}
& \text { 'Why did Saeed go to the market?' }
\end{aligned}
$$

From the sentences in (13), (14), and (15), it can be pointed out that wh-word movement from non-argument positions, more particularly adverbial positions, can be derived in Najrani Arabic VSO word order. The non-argument wh-word raises overtly from its original position in the sentence to the clause-initial position of Spec-CP to satisfy the Edge feature on the phase head C of CP. The question is: Does SVO word order allow wh-word movement from non-argument positions in Najrani Arabic grammar? The next sub-section demonstrates this issue in detail. 


\subsubsection{The Derivation of Wh-questions in SVO Word Order}

Let us discuss the derivation of wh-questions in SVO word order in Najrani Arabic and see whether or not it allows the formation of such interrogatives. The question that can arise here is this: Does Najrani Arabic permit the extraction of subject and object wh-questions from both the subject and object positions in SVO word order? To account for this question, let us first explore the wh-extraction from the subject position, as demonstrated in (16) below.

Wh-extraction from argument positions: the subject position

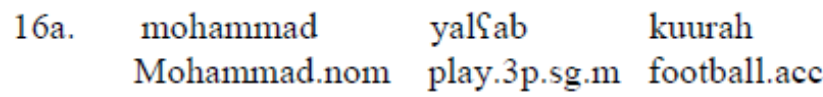

$$
\begin{aligned}
& \text { 'Mohammad is playing football.' }
\end{aligned}
$$

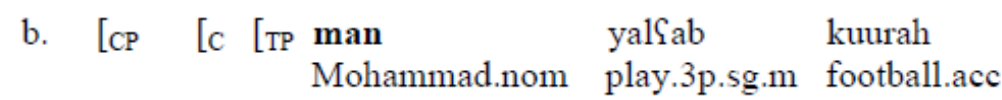

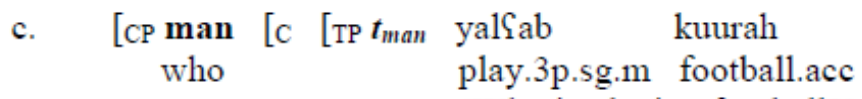

$$
\begin{aligned}
& \text { 'Who is playing football?' }
\end{aligned}
$$

A closer look at the data in (16) reveals that Najrani Arabic allows the subject wh-extraction from the subject position in SVO word order in overt syntax. This means that Najrani Arabic permits the overt raising of the subject wh- phrases from both VSO and SVO word orders, as shown in (10), (11), and (16) above. The wh-question phrase raising is motivated by the morpho-syntactic requirement of the Edge feature on the head C; man 'who' has to raise to [Spec-CP] to satisfy the Edge feature and get the wh-feature valued in the syntax. Given this, we assume that, in the derivation of wh-questions in Najtani Arabic, VSO word order is the unmarked order whereas SVO is the marked order. This conclusion is not in agreement with Fakih's and Al-Sharif's $(2016,2017)$ analysis of, case assignment, agreement and word order in Najrani Arabic. Fakih and Al-Sharif $(2016,2017)$ assume that VSO word order is the marked order whereas SVO is the unmarked order in declarative sentences in Najrani Arabic. On the basis of the preceding discussion, it can be concluded that Najrani Arabic allows the subject wh-extraction from the subject positions in VSO and SVO word orders. But what about the extraction of the object wh-phrase in SVO word order. The next section explores this issue in detail.

\section{Wh-extraction from the argument positions: the object position}

The question is: How is the object wh-question derived in Najrani Arabic syntax? Do SVO and VSO word orders allow the extraction of the object wh-phrase in the language? Let us consider the examples in (17) to illustrate the point, where (16) are reproduced as (17) for convenience. 


\section{7a. [TP mohammad yal؟ab kuurah] \\ Mohammad.nom play.3p.sg.m football.acc \\ 'Mohammad is playing football.'}

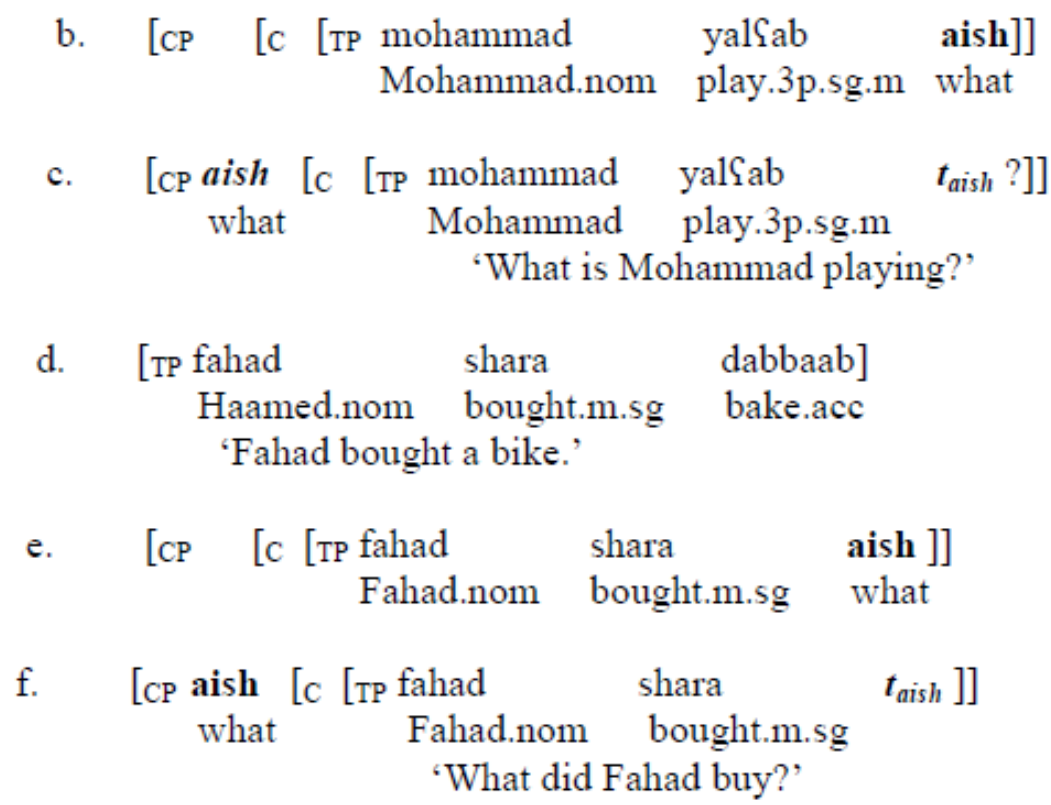

It should be mentioned that almost all the native speakers of Najrani Arabic confirm that the normal word order for the derivation of wh-questions is the unmarked VSO. We have consulted different sample groups of university lecturers, college graduates, and common people about the data of Najrani Arabic; they stress that the normal word order for forming wh-questions is VSO, not SVO. However, a few native speakers of Najrani Arabic indicate that wh-questions in (17) above are acceptable and that SVO word order can also be used to derive wh-interrogatives in the language.

On the other hand, it can be observed in the sentences in (17) that the extraction of wh-questions from the object position is not preferable; the majority of the informants of Najrani Arabic do not prefer the derivation of wh-questions in SVO word order because of the presence of the subject NP immediately after the moved object wh-word. That is, the object wh-word/phrase cannot cross over the subject NP in the process of deriving the wh-question in SVO word order. Moreover, they confirm that (17c) and (17f) are not preferably used in the language. They prefer to derive wh-questions from the object position in VSO word order, as shown in (18) below, but not from SVO order.

$$
\begin{gathered}
{[\mathrm{CP} \text { aish [C [TP shara }} \\
\text { what } \\
\begin{array}{c}
\text { bought.m.sg Fahad.nom } \\
\text { 'What did Fahad buy?' }
\end{array}
\end{gathered}
$$

For the native speakers of Najrani Arabic, the derivation of the object wh-question in (18) is acceptable whereas those in (17c) and (17f) above are not preferably used: the former is in VSO while the latter is in SVO. 


\section{Macrothink}

International Journal of Linguistics

ISSN 1948-5425

2019, Vol. 11, No. 5

Based on the preceding discussion, it can be observed that VSO word order in Najrani Arabic allows the derivation of wh-questions from the subject and object positions whereas SVO order only permits subject wh-movement, but not the object wh-movement, according to the views of the majority of the native speakers. Given this, we assume that VSO word order is the unmarked order for the derivation of wh-questions in Najrani Arabic whereas SVO is the marked order.

\section{Wh-extraction from non-argument positions: adverbial positions}

We have already discussed wh-extraction from non-argument positions in VSO word order in Najrani Arabic and have pointed out that it is allowed in the syntax. In this sub-section, however, we address wh-extraction from non-argument positions, more particularly adverbial positions, in SVO word order in Najrani Arabic. The question is: What about the derivation of wh-questions from adverbial positions in SVO order? Let us illustrate this in (19-21) below.

\begin{tabular}{|c|c|}
\hline 19a. & $\begin{array}{c}\text { [TP al-subai raaH el-souq] } \\
\text { the.boy.nom went the.market.acc } \\
\text { 'The boy went to the market.' }\end{array}$ \\
\hline b. & 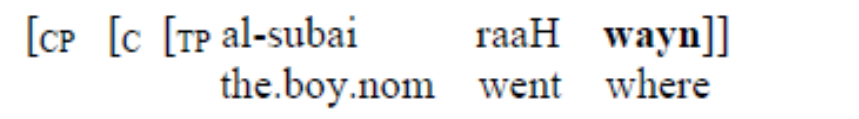 \\
\hline c. & $\begin{array}{l}{\left[\mathrm{CP} \text { wayn }\left[\mathrm{C}\left[\mathrm{TP} \text { raaH al-subai } \boldsymbol{t}_{\text {wayn }} \text { ?] }\right]\right.\right.} \\
\text { where went the.boy.nom } \\
\text { 'Where did the boy go?' }\end{array}$ \\
\hline 20a. & $\begin{array}{l}\text { [TP Sili } \quad \text { saafar } \quad \text { al-baareHah] } \\
\text { Ali.nom travelled last night } \\
\text { 'Ali travelled last night.' }\end{array}$ \\
\hline b. & {$\left[\begin{array}{llll}\mathrm{CP} & {[\mathrm{C}[\mathrm{TP} \text { Sili }} & \text { saafar } & \text { məta }] \\
& \text { Ali.nom } & \text { travelled } & \text { when }\end{array}\right.$} \\
\hline c. & $\begin{array}{l}\text { [CP məta [C [TP Sili } \quad \text { saafar } \\
\text { when Alinom travelled } \\
\text { 'When did Ali travel?' }\end{array}$ \\
\hline
\end{tabular}
21a [TP saeed raaH el-souq yashtari sayyarah] Saeed.nom went the.market.acc buy car.indef 'Saeed went to the market to buy a car.'
b. $[\mathrm{CP} \quad[\mathrm{C}[\mathrm{TP}$ saeed $\mathrm{raaH}$ el-souq liih $]]$ Saeed.nom went the.market.acc where
c. [CP liih [c [TP saeed raaH el-souq $t_{\text {liih }}$ ?] why Saeed.nom went the.market.acc
'Why did Saeed go to the market?'


A thorough investigation into the sentences in (19), (20), and (21) reveal that the majority of the Najrani Arabic speakers do not prefer the formation of adverbial wh-questions in SVO word order. That is, the native speakers of Najrani Arabic do not tend to use them in their daily life conversations; they prefer to use such wh-constructions in (19-21) in the normal VSO word order. However, a few native speakers of Najrani Arabic argue that such adverbial wh-questions in (19-21) are acceptable for them. Based on the preceding discussion, we can conclude that almost all the native speakers view VSO as the unmarked word order while SVO as the marked order for deriving wh-questions in Najrani Arabic.

5.2.3 The Interaction Between the Derivation of Wh-questions in Najrani Arabic and Chomsky's Phase Approach

This section is assigned to explore the interaction between the derivation of wh-questions in Najrani Arabic and Chomsky's (2001, 2005, 2008, 2013, 2015) Phase approach and then present a unified account of wh-questions in Najrani Arabic within Chomsky's Phase framework. We have already pointed out that VSO is the unmarked word order for the derivation of wh-questions while SVO is the marked order in Najrani Arabic. In what follows we analyze wh-questions in VSO word order in both argument and non-argument positions of intransitive and transitive structures, since it is the right word order for the derivation of wh-questions and is used by almost all the native speakers of Najrani Arabic. Beside, we address how wh-questions in SVO word order can be accounted for in Najrani Arabic in the light of Chomsky's Phase analysis, given the recent developments in syntactic theory posed by minimalism.

\subsubsection{Subject Wh-raising From Intransitive Constructions}

Wh-extraction from the subject position in intransitive constructions in Najrani Arabic deserves special attention in minimalist syntax. The objective of the study is to provide a detailed account of how subject wh-raising behaves morpho-syntactically while deriving the wh-question within Chomsky Chomsky's (2001, 2005, 2013, 2015) Phase approach. Let us demonstrate the point in the following intransitive examples from Najrani Arabic in (22) and (23).

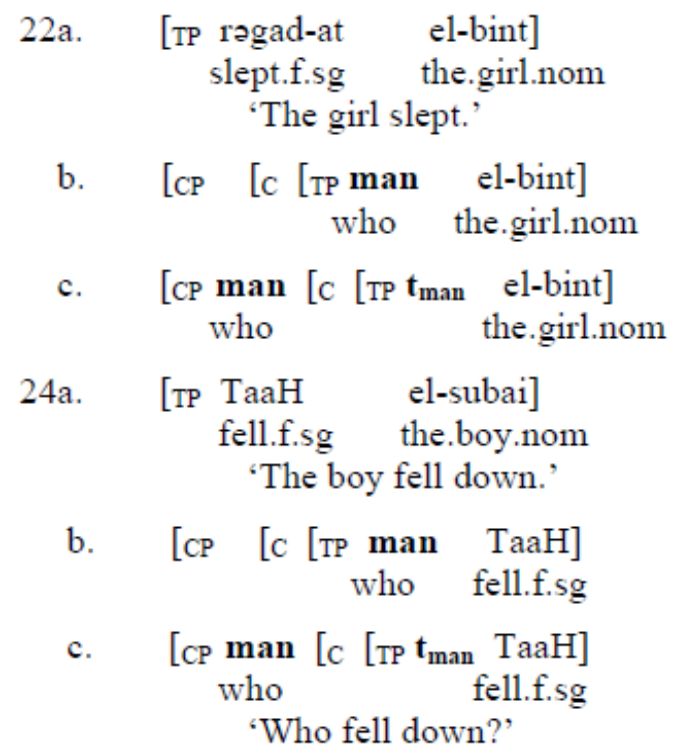


It can be noted that the sentences in (22) and (23) are intransitives wh-questions, where the wh-phrase undergoes obligatory raising to the interrogative phase head $\mathrm{C}$ of $\mathrm{CP}$ for feature valuation in the syntax. In order to provide a neat treatment of the interaction between wh-questions in Najrani Arabic and Chomsky's Phase approach, let us represent morpho-syntactically the sentence in (22a) on a clause structure of Najrani Arabic to show the process of Chomsky's proposed phases in the derivation of wh-phrases in the language, as illustrated in (24) below.

24

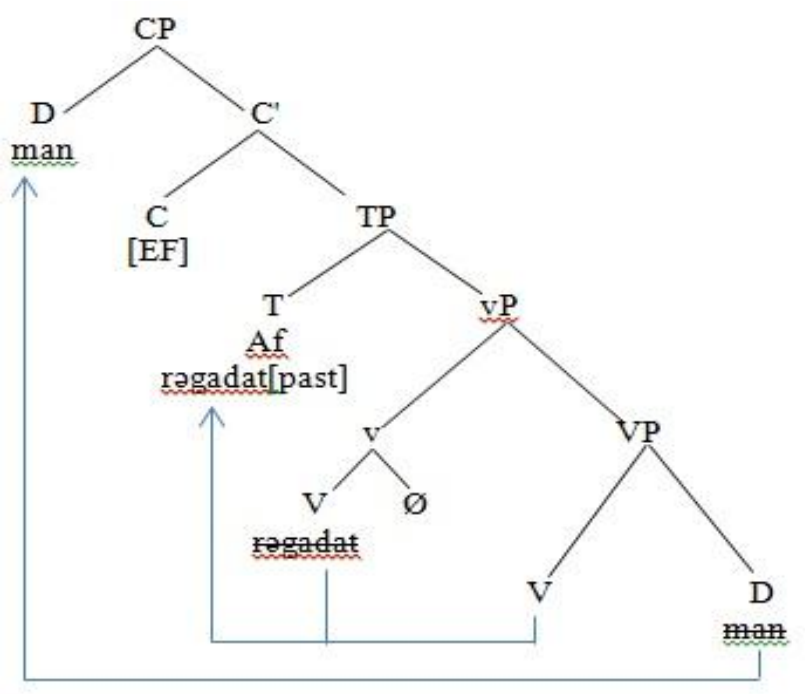

The clause structure in (24) demonstrates the morpho-syntactic analysis of Chomsky's (2000, 2001, 2005, 2013, 2015) Phase theory and shows how the subject wh-movement proceeds in the minimalist syntax. The interaction between the raising of wh-question in Najrani Arabic and Chomsky's model goes in the following manner. The V ragadat 'slept' merges with the D wh-word man 'who' to form the VP projection. In turn the VP merges with the higher light affixal $\mathrm{v}$ which motivates raising of the $\mathrm{V}$ ragadat 'slept' to adjoin to it in order top from the $\mathrm{vP}$ projection. What is really interesting here is that since the clause in (24) is intransitive, the $\mathrm{vP}$ does not have a specifier and that it does not have an external thematic argument either. A closer look at the clause structure in (24) shows that the vP is not a phase, and consequently, a $v$ is not a head, and yet it is not a probe, to use Chomsky's terminology of Phase theory. The consequence that $\mathrm{vP}$ is not a phase is that its VP domain will not be able to be transferred to the PF and LF interface levels in the syntax, which means that the computational system continues in the course of the derivation of the wh-question in (24). Furthermore, the whole $\mathrm{vP}$ merges with an abstract past tense af(fix) on the head $\mathrm{T}$ of $\mathrm{TP}$, a process that results in nominative case assignment; the head $\mathrm{T}$ agrees with and assigns invisible nominative case to the subject wh-word man 'who'. It can be noted that the whole TP merges with a null interrogative phase head $\mathrm{C}$ of $\mathrm{CP}$; the phase head $\mathrm{C}$ has an Edge feature that attracts the raising of the subject wh-word man 'who' to Spec-CP position. Since the subject wh-word has been accomplished in the syntax, the Edge feature is deleted in the course of the derivation of the wh-construction in Najrani Arabic. Being strong and affixal, the head T motivates the raising of the complex $[\mathrm{V}+\mathrm{v}]$ to adjoin to it. Moreover, let us discuss the $\mathrm{CP}$ phase in (24) and how the wh-question proceeds further. Since CP is a phase, its TP domain 


\section{Ml Macrothink}

International Journal of Linguistics

ISSN 1948-5425

2019, Vol. 11, No. 5

has to be sent to the PF and LF components for a proper interpretation. The question is: What about the lower copies left after movement? The answer is that the lower copies of all the moved elements/constituents will receive a null spellout in the phonological component in the syntax. In addition, the head $\mathrm{T}$ and the complex $[\mathrm{V}+\mathrm{v}]$ verb will show up as past. As the interrogative construction is arriving at an end in the course of the syntactic derivation, the subject wh-word man 'who' and the interrogative phase head C must be transferred to the PF and LF interface levels for the appropriate interpretation, the wh-question clause is interpreted as interrogative in Najrani Arabic syntax. Now what about the syntactic derivation of the subject-phrase raising in transitive structures in Najrani Arabic? The next sub-section discusses this issue in detail.

\subsubsection{Subject Wh-raising From Transitive Constructions}

This sub-section attempts to show how the subject wh-phrase can be derived in transitive sentences in Najrani Arabic and to what extent the analysis of the subject in transitive constructions provide interesting facts that may differ from that of intransitive structures in the light of Chomsky's Phase framework. This can be illustrated in (25).

$$
\begin{aligned}
& \text { 25a. [TP kela-t zainab al-tuffaahah] } \\
& \text { ate.past.f.sg Zainab.nom the.apple.acc } \\
& \text { 'Zainab ate the apple.' } \\
& \text { b. } \quad\left[\begin{array}{cc}
\mathrm{CP} \quad[\mathrm{c}[\mathrm{TP} \text { kəla-t } \\
\text { ate.past.f.sg }
\end{array} \underset{\begin{array}{c}
\text { man } \\
\text { who }
\end{array}}{\begin{array}{r}
\text { al-tuffaahah }] \\
\text { the.apple.acc }
\end{array}}\right. \\
& \begin{array}{c}
\text { c. [CP } \operatorname{man}[\mathrm{C} \text { [TP kəla-t } \\
\text { who ate.past.f.sg } \\
\text { 'Who ate the apple?' }
\end{array}
\end{aligned}
$$

Let us now represent (25a) on a clause structure of Najrani Arabic and examine the interaction between Chomsky's analysis of Phase theory and the subject wh-extraction from transitive sentences. This can be demonstrated in (26).

26

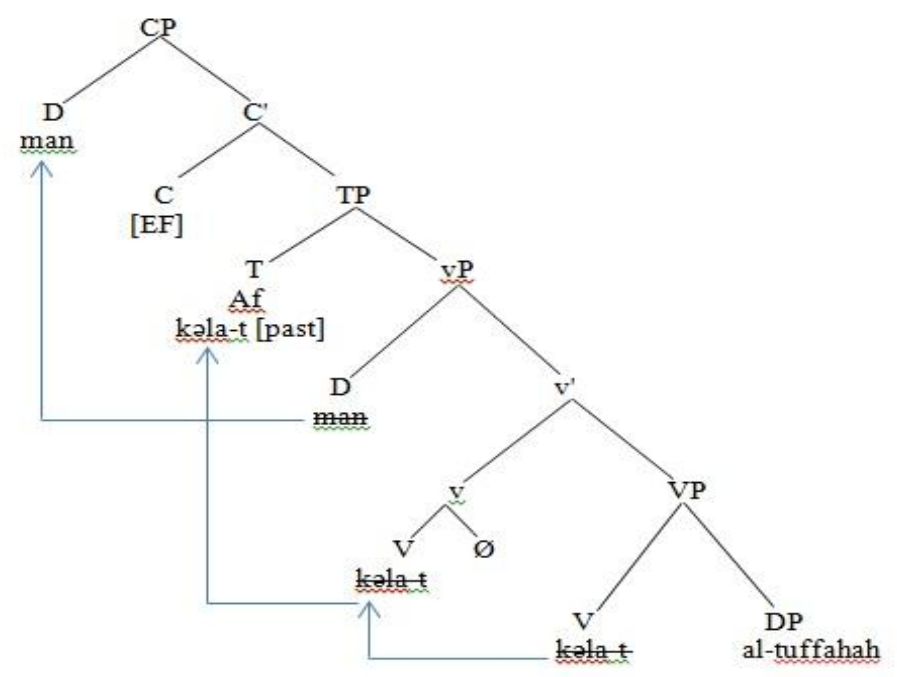




\section{Macrothink}

International Journal of Linguistics

ISSN 1948-5425

2019, Vol. 11, No. 5

The question that arises here is that: Can the subject be treated in transitive constructions in the same way as that in intransitive construction in Najrani Arabic? Given the clause structure in (26), the subject wh-word proceeds in the following manner. The V kala-t 'ate' merges with the object NP al-tuffahah 'the apple', thus forming the VP projection. The VP merges with a light affixal $\mathrm{v}$ in order to form $\mathrm{v}$ '; this light $\mathrm{v}$ attracts movement of the verb kala- $t$ 'ate' to adjoin to it. What is different now from intransitive constructions is that the phase $\mathrm{vP}$ has an external thematic argument (i.e., the subject wh-word man 'who') located in its specifier position. The syntactic process proceeds further, where the $\mathrm{v}^{\prime}$ merges with the subject wh-word in the specifier position of $\mathrm{vP}$ to form a vP. Interestingly enough, the reason why the $\mathrm{vP}$ is treated as a phase in (26) is that the head $\mathrm{v}$ has an external thematic argument, the subject wh-word man 'who'. Consequently, the v acts as the phase head of the vP phase; it is the head which searches for a local goal. That is, the head $\mathrm{v}$ probes for an obligatory complement and locates the object DP complement al-Tuffahah 'the apple' with which it agrees with and assigns accusative case. The requirement of the Phase theory is that since the VP is the vP domain, the former (i.e., VP) must be transferred to the PF and LF interface levels for the necessary interpretation in order for the derivation to converge. Another compulsory requirement of the Phase approach is that the lower copy left behind of the $\mathrm{V}$ receives a null spellout in the phonological component. This ensures that the VP projection cannot be accessed to any further morpho-syntactic operations and that it cannot probe even from outside the vP phase. Moreover, the vP phase proceeds further and merges with the head $\mathrm{T}$ in order to from the TP projection. Not only this, the TP merges with the null phase head $\mathrm{C}$ to from the $\mathrm{C}$-bar. The interesting thing in Najrani Arabic example in (26) is that since the phase head $\mathrm{C}$ has an Edge feature (EF), it projects into the CP. As the head $\mathrm{T}$ is a probe, it has to search for a goal. The head T locates the goal (i.e., the subject wh-word man 'who', being the only available candidate), with which it agrees and assigns invisible nominative case. Since the head T does not have an EPP feature, there will be no movement here; the presence of the EPP feature attracts syntactic movement in the course of the derivation of the wh-construction. The syntactic operations proceed further in the Phase analysis of (26) above. The head phase $C$ is the probe now and has the Edge feature which attracts the syntactic raising of the subject wh-phrase man 'who' to Spec-CP, being an A-bar position. The CP is a phase and the TP is its domain: the latter (i.e., TP) must be transferred to the phonological and semantic interface for the necessary interpretation, this is an obligatory requirement to make sure that the derived wh-question meets the requirements of the minimalist analysis proposed in Chomsky's (2001, 2005, 2008, 2013, 2015) Phase framework. One more step for a successful derivation of the wh-construction in (26) is that the subject wh-phrase man 'who' and the head Phase C have to undergo a compulsory transfer to the PF and LF components, thus ensuring that the wh-structure is interpreted as interrogative in the syntax. Hence, the grammatical wh-question in (26) above has been derived successfully in Najrani Arabic syntax. The next question that needs to be answered is how to account for the object wh-raising from transitive constructions. The next sub-section explores this issue in detail. 


\subsubsection{Object Wh-raising From Transitive Constructions}

Let us analyze the syntax of wh-extraction from the object position and present a unified account of how the object wh-phrase behaves morpho-syntactically in regards to the assumptions of Chomsky's Phase analysis. This can be shown in (27) below.

\section{7a. [TP saag al-rijjaal al-sayyarah] drove the.man.nom the.car.acc \\ 'The man drove the car.'
b. $[\mathrm{CP} \quad[\mathrm{c}[\mathrm{TP}$ saag al-rijjaal aish $]$ drove the.man.nom what
c. [CP aish [c [TP saag al-rijjaal $\left.\mathbf{t}_{\text {aish }}\right]$ what drove the man.nom \\ 'What did the man drive?'}

(27) shows clearly how the wh-phrase from the object position can be derived in Najrani Arabic. Let us represent (27) on a clause structure of Najrani Arabic in (28) and see the interaction between the object wh-phrase and the analysis assumed in the Phase theory of Chomsky.

28

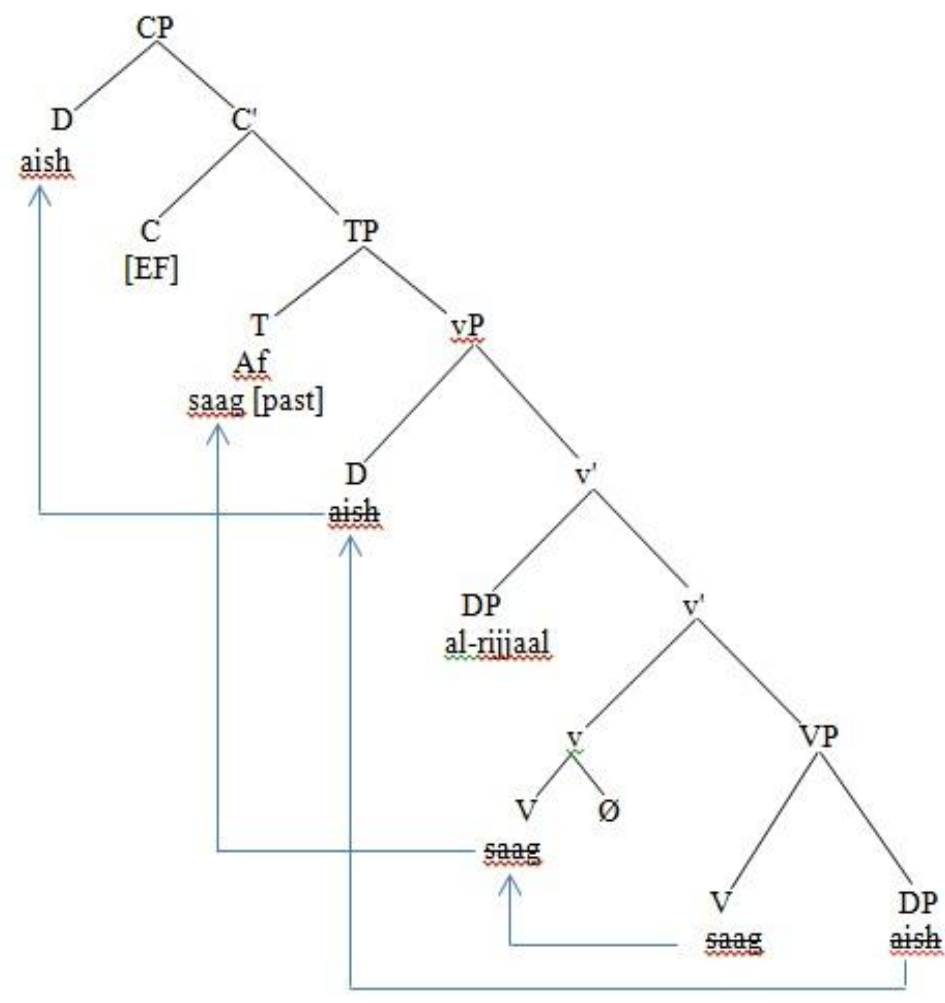

What happens in (28) is that the V saag 'drove' merges with its object complement DP aish 'what' to from the VP; the latter in turn merges with the light $\mathrm{v}$, which attracts raising of the 
$\mathrm{V}$ saag 'drove' to adjoin to it in the course of derivation. Furthermore, the head v merges with the subject DP al-rijjaal 'the man', thus forming the v'. It can be observed that the head $\mathrm{v}^{\prime}$ is a phase for the reason that it has an external thematic argument al-rijjaal, which acts here as the subject of the clause in (28). Since the $\mathrm{v}$ is a phase head, it has to probe for a local goal and hence it finds the object wh-phrase aish 'what'. Consequently, the head v agrees with and assigns accusative case to the object wh-phrase aish 'what'. Based on Chomsky's (2001, 2005, 2008, 2013, 2015) Phase analysis, we assume that, in Najrani Arabic clause structure in (28), the light transitive $\mathrm{v}$, acting as the head of the vP phase, has an Edged feature which has the syntactic power to attract the object wh-phrase aish to be the second (outer) specifier of vP. This line of analysis follows from Chomsky's analysis that a phase head may have multiple specifiers in the syntax. It can be mentioned that the TP domain of the phase vP has to be transferred to the PF and LF components for interpretation. Following this, the null copies of the moved entities left after will movement receive a null spellout in the language and, hence, cannot be accessed any more. The next step is that the vP merges with the head $\mathrm{T}$ to form the TP projection, where the head $\mathrm{T}$ is the probe which probes in order to locate the goal in its governing domain. However, there are two available goals in (28): the first one is the object wh-phrase aish 'what' and the second is the subject wh-phrase al-rijjaal 'the man'. The question is: What about case assignment of the goal? The answer follows from Chomsky's assumption that when the goal's Case has been valued and deleted, as in the case with the object wh-phrase aish 'what', the goal becomes inactive for agreement with or attraction by a head like T of TP. The other interesting observation in Najrani Arabic is that the head T lacks an EPP feature which attracts the syntactic raising. A closer look at the clause structure in (28) reveals that the wh-phrase aish 'what' intervenes between the head T and the subject DP al-rijjaal 'the man'. In order to present a logical explanation for this phenomenon, we assume, following Boeckx's (2007) analysis, that a D like aish 'what' with an already valued accusative Case feature becomes transparent for the head T; it is the head $\mathrm{T}$ which can see through aish 'what' and finds al-rijjaal as the closest active goal. Hence, the head $\mathrm{T}$ agrees with and assigns nominative Case to the subject DP al-rijjaal 'the man'. On the other hand, it should be mentioned that the subject DP al-rijjaal 'the man' remains in situ because the head $\mathrm{T}$ in Najrani Arabic does not have an EPP feature that attracts movement. Being strong and affixal, the head $\mathrm{T}$ attracts the syntactic raising of the complex $\mathrm{V}+\mathrm{v}$ to value the tense feature and provide a host for it. Based on the preceding discussion in Najrani Arabic, we can assume that TP is not a phase. Given this, the derivation proceeds further in (28); the TP projection merges with the null interrogative phase head $\mathrm{C}$ which has an Edge feature; the latter attracts movement of the wh-phrase from the edge of vP to $[\mathrm{Spec}, \mathrm{CP}]$. Furthermore, TP has to be sent to the phonological and semantic interface levels for the proper representation. Eventually, the phase head $\mathrm{C}$ and its specifier aish 'what' will be transferred to the PF and LF components and, consequently, the clause in (28) is interpreted as a wh-interrogative in the minimalist syntax of Najrani Arabic.

\section{Conclusion}

It can be pointed out that the application of Chomsky's Phase analysis on Najrani Arabic wh-questions has successfully provided further evidence of the usefulness of the approach to 
syntactic theory of the world languages. It has successfully answered the two questions of the study and has presented a neat account $\mathrm{t}$ of wh-questions in Najrani Arabic. What distinguishes the Phase theory from other models of syntax is that it is based on practical assumptions and is more economical compared to other complicated syntactic approaches. Concerning the first question, the study has shown that Najrani Arabic allows the derivation of wh-questions from the argument and non-argument positions in VSO word order. It has pointed out that almost all the native speakers of Najrani Arabic strongly agree that VSO is the right word order for the derivation of wh-questions and that they do not prefer the formation of wh-questions in SVO word order. Only a few native speakers still see that SVO word order can also be used to derive wh-questions in the language. Given this, we have assumed that VSO is the unmarked word order for the derivation of wh-questions in Najrani Arabic. Based on the interaction between the Najrani Arabic data and Chomsky's Phase approach with regards to the second question, it has been observed that the subject DP does not raise to Spec-TP in Najrani Arabic VSO, because the head T does not have the EPP feature: the latter (i.e., the EPP feature) attracts movement of the former. The verb raises higher up to the head $\mathrm{T}$ of $\mathrm{TP}$ in the clause structure for feature valuation, while the subject DP remains in-situ in Spec-vP in Najrani Arabic VSO word order. It has been shown that wh-question movement in Najrani Arabic is obligatory and takes place in overt syntax; the wh-word in the argument and non-argument positions raises overtly from its original position to Spec-CP to satisfy the Edge feature on the phase head $\mathrm{C}$ of $\mathrm{CP}$. The interesting observation in Najrani Arabic intransitive structures is that the $\mathrm{vP}$ does not have a specifier and that it does not have an external thematic argument either; the vP is not a phase, and consequently, a $\mathrm{v}$ is not a head, and yet it is not a probe. However, in Najrani Arabic transitive constructions, the phase vP has an external thematic argument (i.e., the subject wh-word man 'who') located in its specifier position. The reason why the vP is treated as a phase in transitive constructions is that the head $\mathrm{v}$ has an external thematic argument, the subject wh-word man 'who'. Concerning case assignment of the subject wh-word, the whole vP merges with an abstract past tense af(fix) on the head $\mathrm{T}$ of $\mathrm{TP}$; the head $\mathrm{T}$ agrees with and assigns invisible nominative case to the subject wh-word man 'who'. It can be noted that the whole TP merges with a null interrogative phase head $\mathrm{C}$ of $\mathrm{CP}$; the phase head $\mathrm{C}$ has an Edge feature that attracts the raising of the subject wh-word man 'who' to Spec-CP position. Since the subject wh-word raising has been accomplished in the syntax, the Edge feature is deleted in the course of the derivation of the wh-construction in Najrani Arabic. We have assumed that the phase head $\mathrm{C}$ is the probe and has the Edge feature which attracts the syntactic raising of the subject wh-phrase man 'who' to Spec-CP, being an A-bar position. Moreover, we have assumed that the light transitive phase head $\mathrm{v}$ in Najrani Arabic has an Edged feature which attracts the raising of the object wh-phrase aish to be the second (outer) specifier of vP. It has been shown that the $\mathrm{v}$ is the phase head and needs to probe for a local goal; it finds the object wh-phrase aish 'what'. Consequently, the head v agrees with and assigns accusative case to the object wh-phrase aish 'what'. As the whole TP merges with a null interrogative phase head $\mathrm{C}$ of $\mathrm{CP}$, the phase head $\mathrm{C}$ has an Edge feature that attracts the raising of the object wh-word aish 'what' to Spec-CP for feature valuation in the syntax. 


\section{Macrothink}

International Journal of Linguistics

ISSN 1948-5425

2019, Vol. 11, No. 5

\section{Acknowledgements}

The author would like to thank the anonymous reviewers for their valuable comments and suggestions on the earlier draft of this paper. I would also like to thank all my informants who provided all the necessary data about Najrani Arabic; their assistance is highly appreciated.

\section{References}

Abdel Razaq, I. (2011). Who is what and what is who: the morpho-syntax of Arabic WH. Unpublished PhD Thesis, Queen Mary, University of London.

Abu-Jarad, H. (2008). Wh-movement in Palestinian Arabic. Al-Azhar University Journal at Gaza, 10(1), 49-62.

Abu-Sulaiman, J. (2007). The effects of the tense of the clause on the wh-phrase in wh-in-situ Makkan Arabic from the minimalist perspective. Unpublished M.A Dissertation, Umm Al-Qura University, KSA.

Al-hamami, A., \& Al-fadly, H. (2018). Wh-movement in Najrani Arabic. International Journal of Language and Literature, 1(6), 111-118.

Al-Momani, I. (2010). Direct object relative clauses in Jordanian Arabic: a minimalist approach. International Journal of Academic Research, 2, 226-237.

Al-Momani, I., \& Al-Saiat, E. (2010). The syntax of wh-movement in Jordanian Arabic. European Journal of Scientific Research, 40, 609-628.

Alotaibi, M. (2013). A problem with wh-questions in Modern Standard Arabic. Proceedings of Language at the University of Essex, 1-8.

Al-Sager, H. N. (2017). Phasehood of wh-questions in Modern Standard Arabic. Unpublished PhD dissertation, Arizona State University.

Al-Shorafat, M. (2013). A phase-based account of wh-questions in Standard Arabic. Linguistics and Literature Studies, 1(4), 179-190.

Al-Touny, K. (2011). Question formation between the Minimalist Program and Optimality Theory. Unpublished M.A Thesis, Ain Shams University, Cairo.

Aoun, J., \& Li, A. (1993). Wh-elements in situ: syntax or LF?. Linguistic Inquiry, 24, 199-238.

Aoun, J., \& Li, A. (2003). The diversity of wh-constructions: essays on the representational and derivational nature of grammar. Cambridge, MA.: The MIT Press.

Aoun, J., \& Lina, C. (1998). Modes of interrogation. In E. Benmamoun (Ed.), Perspectives on Arabic Linguistics: Papers from the Annual Symposium on Arabic Linguistics Volume XII (pp. 7-26). Amesterdam: John Benjamins.

Aoun, J., Benmamoun, E., \& Choueiri, L. (Eds.) (2010). The syntax of Arabic. Cambridge: Cambridge University Press. 
Bach, E. (1971). Questions. Linguistic Inquiry, 2, 153-166.

Bardeas, S. M. (2005). The pronominal forms in questions in Makkan Arabic. Unpublished M.A Dissertation, University of York.

Boeckx, C. (2007). Understanding minimalist syntax. Oxford: Blackwell.

Cheng, L. (1991). On the typology of wh-questions. Doctoral Dissertation. MIT.

Cheng, L. (1997). On the typology of wh-questions. New York: Garland Publishing.

Chomsky, N. (1957). Syntactic Structures. The Hague: Mouton.

Chomsky, N. (1977b). On wh-movement. In P. W. Culicover, T. Wasow, \& A. Akmajian (Eds.), Formal Syntax (pp. 71-132). New York: Academic Press.

Chomsky, N. (1981). Lectures on government and binding. Dordrecht: Foris.

Chomsky, N. (1986a). Barriers. Cambridge, MA.: MIT Press.

Chomsky, N. (1995). The Minimalist Program. Cambridge, MA.: the MIT Press.

Chomsky, N. (1998, 2000). Minimalist inquiries: the framework, Preliminary version in MIT Working Papers in Linguistics no. 15. In Martin, R., Michaels, D., \& Uriagereka, J. (Eds.), Step by Step: Essays on Minimalist Syntax in Honor of Howard Lasnik. Cambridge, MA.: MIT Press.

Chomsky, N. (1999). Derivation by phase. Ms. Cambridge, MA.: MIT.

Chomsky, N. (2000). Minimalist inquiries: the framework. In R. Martin, D. Michaels, \& J. Uriagereka (Eds.), Step by Step: Essays on Minimalist Syntax in Honor of Howard Lasnik (pp. 89-155). Cambridge, Mass: MIT Press.

Chomsky, N. (2001). Beyond explanatory adequacy. Ms. Cambridge, MA.: MIT.

Chomsky, N. (2005a). On phases. Ms. Cambridge, MA.: MIT.

Chomsky, N. (2005b). Three factors in language design. Linguistic Inquiry, 36, 1-22.

Chomsky, N. (2006). Approaching UG from below. Unpublished paper. MIT.

Chomsky, N. (2007). Approaching UG from below. Interfaces+Recursion= Language?. In U. Sauerland, \& Hans-MartinGärtner (Eds.), Chomsky's Minimalism and the View from Syntax-Semantics (pp. 1-29). Mouton de Gruyter, Berlin.

Chomsky, N. (2008). On phases. In R. Freidin, C. P. Otero, \& M. Luisa Zubizarreta (Eds.), Foundational Issues in Linguistic Theory: Essays in Honor of Jean-Roger Vergnaud, (pp. 133-166). MIT Press, Cambridge, MA.

Chomsky, N. (2013). Problems of projections. Lingua, 130, 33-49

Chomsky, N. (2015). Problems of projection: Extensions. In E. Di Domenico, C. Hamann, \& S. Matteini (Eds.), Structures, strategies and beyond: Studies in honour of Adriana Belletti 


\section{I Macrothink}

International Journal of Linguistics

ISSN 1948-5425

2019, Vol. 11, No. 5

(pp. 1-16). Linguistik Aktuell/Linguistics Today, 223. Amsterdam, The Netherlands: John Benjamins.

Culicover, P. W. (1976). Syntax. New York: Academic Press.

Denham, K. (2000). Optional wh-movement in Babine Witsuwit'en. Natural Language and Linguistic Theory, 18, 199-251.

Fakih, A. (2007a). Wh- and multiple wh- questions in Standard Arabic, English, and the Slavic languages and LF-representation. The University Researcher Journal, 13, 1-28.

Fakih, A. (2007b). Licensing: movement and feature checking in Standard Arabic and minimalism. Journal of King Saud University, 19, 37-54.

Fakih, A. (2011). The syntax of questions in Modern Standard Arabic: A minimalist perspective. London: Amazon Publishing.

Fakih, A. (2014). Subject wh-movement in Najrani Arabic and minimalism. International Journal of Linguistics, 6(5), 80-108.

Fakih, A. (2015). Wh-questions in Hodeidi Arabic: a phase-based approach. Theory and Practice in Language Studies, 5(4), 773-783.

Fakih, A. (2016). An agree-based approach to structural case assignment in Najrani Arabic. International Journal of Applied Linguistics \& English Literature, 5(5), 119-138.

Fakih, A. (2017). The syntax of word order derivation and agreement in Najrani Arabic: a minimalist analysis. English Language Teaching, 10(2), 48-63.

Gad, R. F. (2011). A syntactic study of wh-movement in Egyptian Arabic within the minimalist program. Unpublished $\mathrm{PhD}$ Thesis, University of Leeds.

Haegeman, L. (1994). Introduction to government and binding theory. Second Edition. Oxford: Blackwell.

Lassadi, B. (2003). Optional wh-movement $\mathrm{m}$ French and Egyptian Arabic. Cohiers Linguistiques d'Ottawa, 31, 67-93.

Leung, T., \& Al-eisaei, F. (2011). Wh-fronting and wh-cleft in Emirati Arabic. Manuscript, UAE University.

Nouhi, Y. (1996). Wh-constructions in Moroccan Arabic. Unpublished M.A Thesis, University of Ottawa.

Ouhalla, J. (1996). Remarks on the binding properties of wh-pronouns, Linguistic Inquiry, 27, 676-707.

Pesetsky, D. (1987). Wh-in-situ: movement and unselective binding. In Reuland, E., \& Meulen, A. (Eds.), The representation of (in) definiteness (pp. 98-129). Cambridge, MA: MIT Press.

Radford, A. (1981). Transformational syntax. Cambridge: Cambridge University Press. 


\section{Macrothink}

International Journal of Linguistics

ISSN 1948-5425

2019, Vol. 11, No. 5

Radford, A. (1988). Transformational grammar. Cambridge: Cambridge University Press.

Rizzi, L. (1997). The fine structure of the left periphery. In L. Haegeman, (Ed.), Elements of grammar: a handbook of generative syntax (pp. 281-337). Kluwer: Dordrecht.

Rizzi, L. (2001). Relativized minimality effects. In Baltin, M., \& Collins, C. (Eds.), The handbook of contemporary syntactic theory (pp. 89-110). Oxford: Blackwell.

Simpson, A. (2000). WH-movement and the theory of feature checking. John Benjamins Publishing.

Shlonsky, U. (2002). Constituent questions in Palestinian Arabic. In Ouhalla, J., \& Shlonsky, U. (Eds.), Themes in Arabic and Hebrew syntax (pp. 137-159). Dordrecht: Kluwer.

Sultan, U. (2010). On licensing wh-scope: wh-questions in Egyptian Arabic revisited. In Bassiouney, R., \& Katz, G. (Eds.), Proceedings of the 2010 Georgetown University Round Table on Arabic Language and Linguistics. Washington, DC: George Town University Press.

Wahba, W. (1984). Wh-constructions in Egyptian Arabic. PhD dissertation, University of Illinois, Urbana-Champaign.

Wahba, W. (1991). LF movement in Iraqi Arabic. In Huang, C-T., \& May, R. (Eds.), Logical structure and linguistic structure (pp. 253-276). Dordrecht: Kluwer.

Watanabe, A. (1991). Wh-in-situ, subjacency and chain formation. Ms, MIT.

Yassin, A. (2013). Syntax-prosody interface: wh-movement in Jordanian Arabic and Egyptian Arabic. Studies in the Linguistic Sciences: Illinois Working Papers, 37-52.

\section{Copyrights}

Copyright for this article is retained by the author(s), with first publication rights granted to the journal.

This is an open-access article distributed under the terms and conditions of the Creative Commons Attribution license (http://creativecommons.org/licenses/by/4.0/) 